Dig Surg 1995;12:3

\title{
Contents, Vol. 12, No. 1, 1995
}

\section{Fan, ST.; Wong, J.}

Preface

5

Tsai, S.-L.; Liaw, Y.-F.

Etiology and Pathogenesis of Hepatocellular Carcinoma

7

Ng, I.O.L.

Pathological Features and Pathological Prognostic Indicators in Hepatocellular Carcinoma 16

Ohtomo, K.; Itai, Y.

Imaging of Hepatocellular Carcinoma

22

Nagasue, N.; Hayashi, T.; Uchida, M.

Techniques of Hepatectomy for Hepatocellular Carcinoma

34

Kawasaki, S.; Makuuchi, M.; Miyagawa, S.

Resection of Hepatocellular Carcinoma Associated with Cirrhosis

40

Que, F.G.; Nagorney, D.M.

Hepatocellular Carcinoma: A Western Perspective

45

Fan, ST.; Tsui, S.L.

Peri-Operative Care of Patients with Hepatocellular Carcinoma Undergoing Hepatectomy 53

Rogiers, X.; Knoefel, W.T.; Malagó, M.; Stemeck, M.; Broelsch, Ch.E.

Liver Transplantation for Hepatocellular Carcinoma

61

Ngan, $\mathrm{H}$.

Interventional Radiology for Hepatocellular Carcinoma

65

Sitzmann, J.V.; Abrams, R.A.

Radiation and Chemotherapy for Hepatocellular Cancer

73

Kang, J.Y.; Guan, R.

Early Detection of Hepatocellular Carcinoma

79

Author Index

85 
Subject Index 86

3 